\title{
Heritage Conservation and New Plan of the Deshou Palace Block
}

\section{Peifang Sun}

School of Civil Engineering and Architecture, Zhejiang University of Science and Technology, Hangzhou, China

Email: 870684984@qq.com

How to cite this paper: Sun, P. F. (2021). Heritage Conservation and New Plan of the Deshou Palace Block. Art and Design Review, 9, 148-155.

https://doi.org/10.4236/adr.2021.92013

Received: May 27, 2020

Accepted: May 15, 2021

Published: May 18, 2021

Copyright () 2021 by author(s) and Scientific Research Publishing Inc. This work is licensed under the Creative Commons Attribution International License (CC BY 4.0).

http://creativecommons.org/licenses/by/4.0/

\begin{abstract}
This article is on the basis of reading much historical document and bookmaking, researching the formation, the background and the geography of the Deshou Palace, and mainly carries research on its location, layout spatial processing, creating artistic mood, and so on. These are useful references to modern urban and architecture design and construction. The conservation of historical sites is not only to satisfy the people's nostalgia for history and culture, but also to continue and meet the needs of urban life. In the conservation and planning of the Deshou Palace, historic sites are the uninterrupted scene of modern life, which makes our lives closely integrated with history, geography and culture. Because of the rational urban design, the relic culture blends with the modern urban life, and a new viable district is formed.
\end{abstract}

\section{Keywords}

Deshou Palace, Hangzhou, Conservation, Historical Sites, Urban Design

\section{Introduction}

DeShou Palace was originally premier Qinhui's mansion and garden of the Southern Song Dynasty. In 1162, Emperor Gaozong of the Song Dynasty, also retreated there after abdication. According to the literature, DeShou Palace covers an area of 170,000 square meters at that time. And its layout is similar to the Imperial City of the Southern Song Dynasty. There are more than ten halls and courtyards, including Deshou Hall, Houdian Hall, Lingzhi Hall, etc. (Zhou, 2007). There are also a large number of garden landscapes, the exquisite degree of which can be compared with the imperial city of the Southern Song Dynasty (Figure 1).

Historically, the transition period of China's gardening technology was during the Song and Yuan Dynasties, and the existing classical gardens in China were 


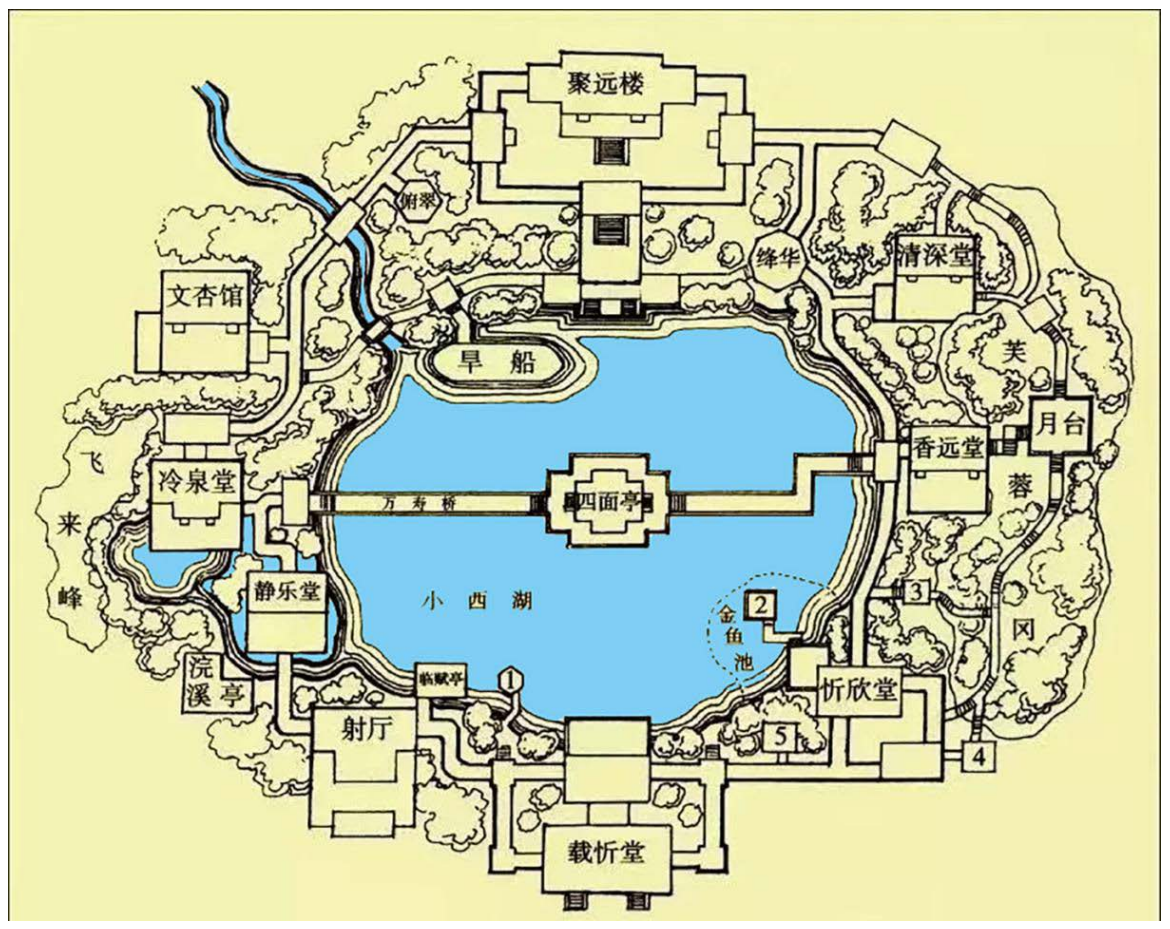

Figure 1. Garden architecture distribution diagram of DeShou in the Southern Song Dynasty (Source: from Shengshi Jinyuan Culture Center).

mainly built in the Ming and Qing Dynasties (Lou, 2016). There are no examples of gardens in Song and Yuan dynasties. The ruins of the Deshou Palace in the Southern Song Dynasty in Hangzhou belong to the ruins of large-scale garden buildings, which undoubtedly can fill the gaps in the gardens' history of the Song and Yuan Dynasties.

\section{Historical and Current Situation Research}

According to the historic literature, it is generally believed that the boundary of the former site of Deshou Palace is: south to Wangxianqiao Straight Street, north to Youshengguan Road, west to Zhonghe River and east to Jixiang Lane. It is worth mentioning that the remains of the East and South Palace walls, 2 or 3 meters underground, were excavated in the reconstruction project of Wangjiang Road in 2001. And then, the western palace wall, a canal to bring water to the garden, and a series of relics such as sluices, pools and wells were discovered (Figure 2). At present, only the North Palace Wall has not been found (Ma, 2018).

Due to the special requirements of conserving the ruins, the development of the site has been greatly constrained, and it has not been well developed and utilized for many years (Figure 3). At present, the eastern part of the site is occupied by a large area of old residential buildings, and the southeast corner is the Wangjiang parking lot. In the western part of Deshou Palace, the current ground floor is the Drum Tower parking lot, and the north side is adjacent to the residential land. Among them, the buildings of No. 3, 17 and 19 of Heng Jixiang 


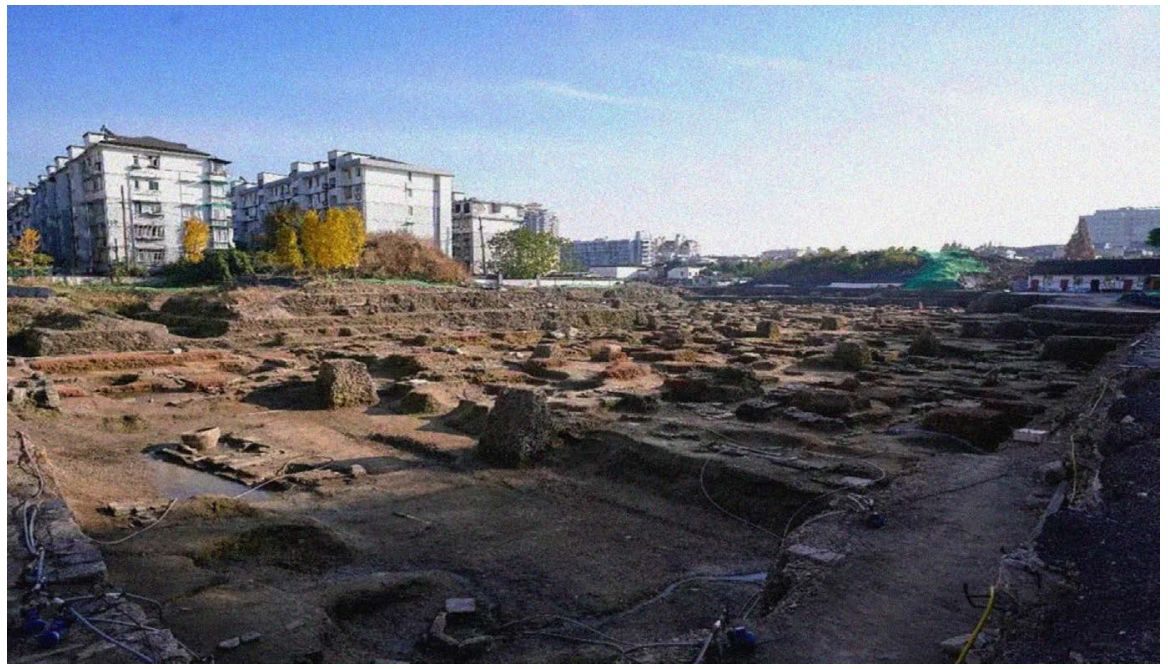

Figure 2. Remains of the pillar foundation of DeShou Palace (Source: from Shengshi Jinyuan Culture Center).

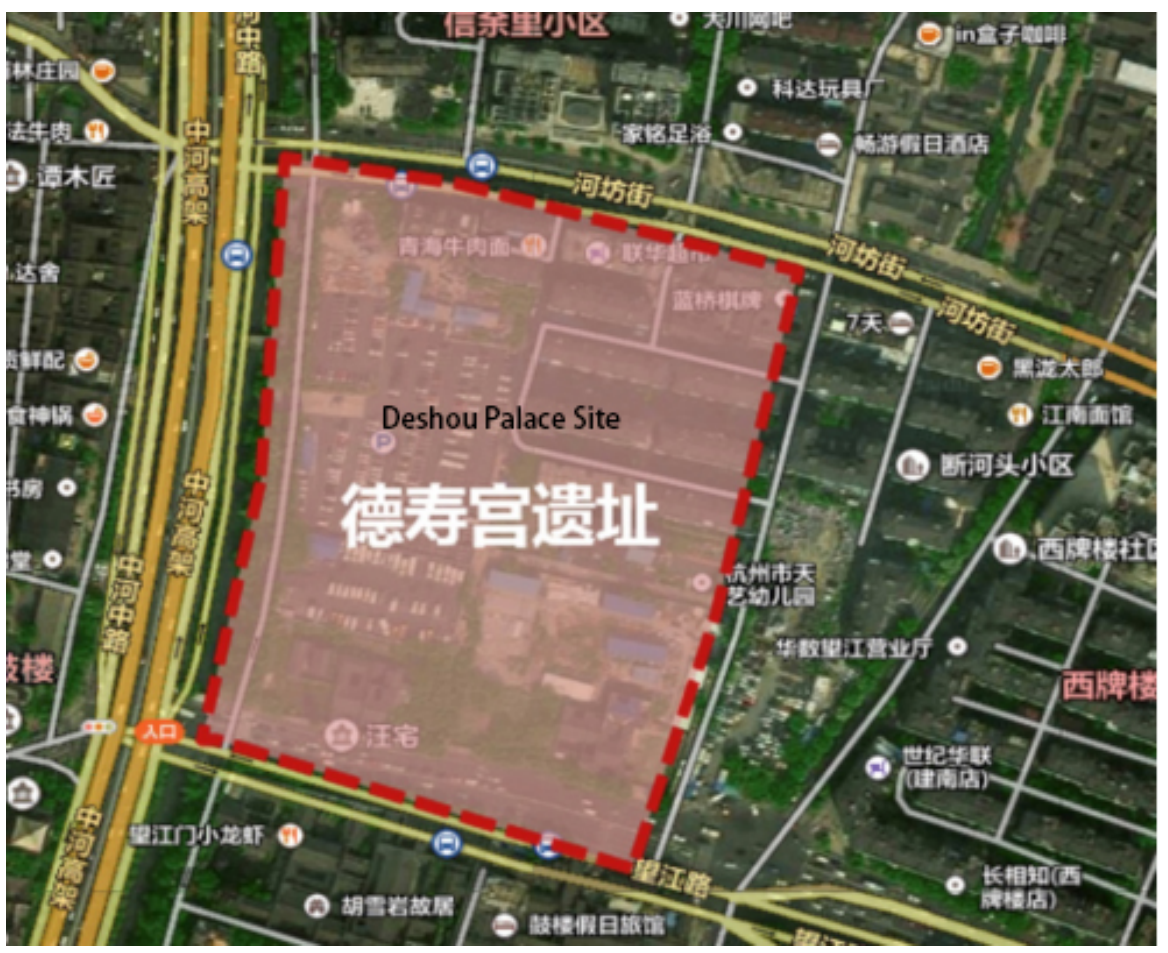

Figure 3. Topographic map of the DeShou Palace site (Source: from Baidu map).

Alley are historical and cultural buildings listed in Hangzhou. Further north, we find Hefang Street and Wuliu Lane. On the south side of the site is Wang Zhai, it's a cultural conservation unit of Hangzhou City. And there is the former residence of Hu Xueyan of the cultural conservation unit across Wangjiang road.

The site of Deshou Palace is not only located in the central plot of the historical and cultural region of Shangcheng District of Hangzhou, but also has a lot of land available for development around it. Urban design that re-integrates the Drum Tower parking lot, Wangjiang parking lot and adjacent industrial land 
and residential land will contribute to the conservation and display of historical resources. It can also be combined with other historical buildings and cultural conservation units in the area to create a bright spot in the area.

\section{Guiding Ideology and Principles for Cultural Conservation of the DeShou Palace}

In order to meet the requirements of historical building conservation, we believe that the design of Deshou Palace section protection planning should follow the following guidelines:

1) Reasonably conserve and display the underground remains of Deshou Palace: column foundation, building components, sluice gates, canals, etc. In order to fully demonstrate the cultural connotation and value of the site, it is necessary to display the ruins as a carrier. At present, the domestic and international landscape display modes of ruins can be generally divided into four types: a) Original display, that is the original appearance of the site or the cover display; b) Logo display, including planting turf logo, platform logo, and some ruins repair logo; c) Prompt display, including models, pictures, texts, signs, etc; d) Building Restore and display, usually a new antique building entity. All the four display modes can be used in the context of the conservation and display of the remains of DeShou Palace (Dong, 2014).

In short, DeShou Palace, as a carrier of historical culture, has important cultural values. Only by fully discovering and presenting its Southern Song Dynasty garden and residential culture, and developing it into a historical and cultural education and propaganda base, it can be used to its fullest extent of historical and cultural values. In particular, in order to conserve the underground ruins of DeShou Palace, the plot should be limited to a height of 21 meters and the excavation should be controlled within 3 meters (Dong, 2000). The new building should be based on a flat foundation so that it does not touch the underground site of the DeShou Palace. After the height analysis of the building, the highest commercial building in the surrounding block is 30 meters high, and the residential building is generally six stories high and about 18 meters high. The lowest of the local blocks is the cultural conservation unit and the historical buildings, generally 9 meters high. The volume of these buildings is not much different, so we should design according to this volume when designing. And make sure that the foundations of the new buildings do not disturb and destroy the underground relics.

2) According to the four levels of historical building conservation, the existing buildings in the local section shall be conserved, reconstructed or modified (Figure 4).

a) For immovable cultural heritages, that is the cultural conservation units, for example, Wang Zhai in the southwest corner of the local block, the conservation requirements are the strictest, that is to follow the principle of not changing the original state, and do not arbitrarily relocate cultural relics and monuments, or 


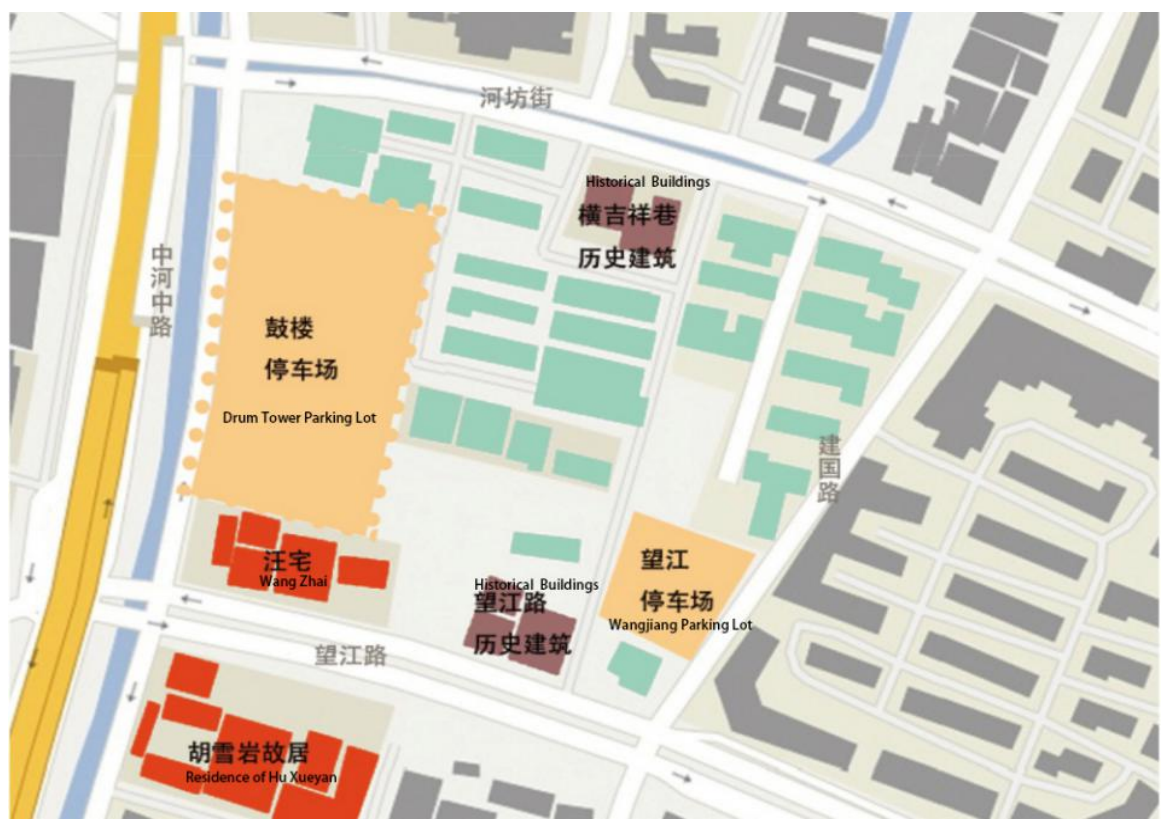

Figure 4. Status of the base: the cultural conservation unit Wang Zhai and several historical buildings (Source: drawn by the author's design team).

rebuild. At present, Wang Zhai is used as a small city exhibition hall and can remain unchanged.

b) For historical buildings, such as No. 220, 222, 224, and 226 of Wangjiang Road and No. 1, 2, 3, 17, 19 of Heng Jixiang lane (Ma, 2018), it is necessary to adhere to: the principle of maximum conservation and minimal transformation. That is to say, we must first actively protect it, we must not dispose of it, and we must not allow large-scale dismantling.

c) For buildings with historical features, the structure, space, function and other aspects can be renavated. For example, the new structural system is used to replace the original damaged structural system, which can also make the indoor space of the traditional building interior space not limited by the original column network, and into a functional space. However, according to field research, local blocks have no buildings that can be defined as historical features.

d) For other buildings, such as residential buildings in the northeast of the plot, old industrial buildings, etc., they can be designed and transformed or modified and rebuilt. However, relevant departments of the government should be combined to take into account the relocation of residents and employees.

3) In the planning and design of the land parcel of deshou palace, the qualitative design and quantitative design should be done reasonably. Qualitative, that is, the implementation of the location nature: for commercial purposes or residential, recreational and other functions of qualitative. On this basis, the study of land use organization and spatial structure is carried out. Quantitative, that is, according to the basic conditions given in the qualitative documents of urban planning, such as plot ratio and greening rate, the total building area, the population contained in the section, and the size and density of each main functional 
unit are preliminarily determined (Yang, 2006).

In short, the qualitative quantification of new blocks and buildings is very important. Before the design, the entire block should be investigated and researched. In the function selection, form design, style inheritance, building height and skyline design, the whole site should be deeply analyzed, and a correct judgment should be made.

\section{Urban Design and Program Strategy}

Relying on the cooperation with teachers and students of Zhejiang University of Science and Technology, we carry out research on conservation planning and design of Deshou Palace (Figure 5), hoping to highlight the original historical features of this area and make it possible to live with the city through environmental remediation and architectural relics. Organically blending and enhancing the neighborhood culture and quality of life in the Deshou area is the aim of the conservation.

Our plan reproduces the prosperous style of the Northern Song Dynasty Bianliang City in the form of modern architecture, in order to restore the sense of living space in the Song Dynasty. Visually giving a sense of unity, the street space is narrow and intimate, and the ratio of the height of the low-rise buildings to the street along the street building is maintained at accepted ratio of 1:1.2. The detailed column is also unified with the whole building. The ground is covered with black tiles, while the walls are mainly made of plain brick wall and whitewashed wall. The architectural style is simple and elegant (Figure 6).

This idea is designed in line with the city planning direction. At the same time, it tries to maximize the use of the historical resources of the Deshou

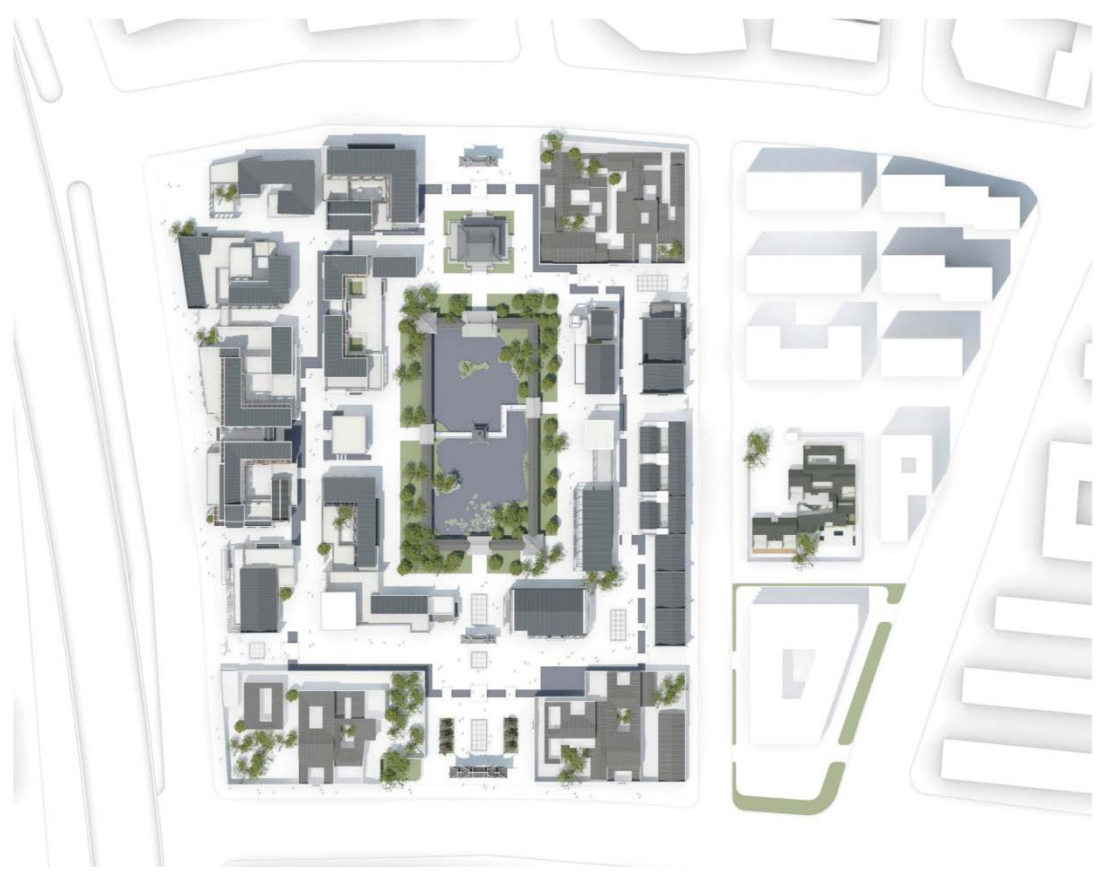

Figure 5. Master plan of our disign (source: drawn by the author's design team). 


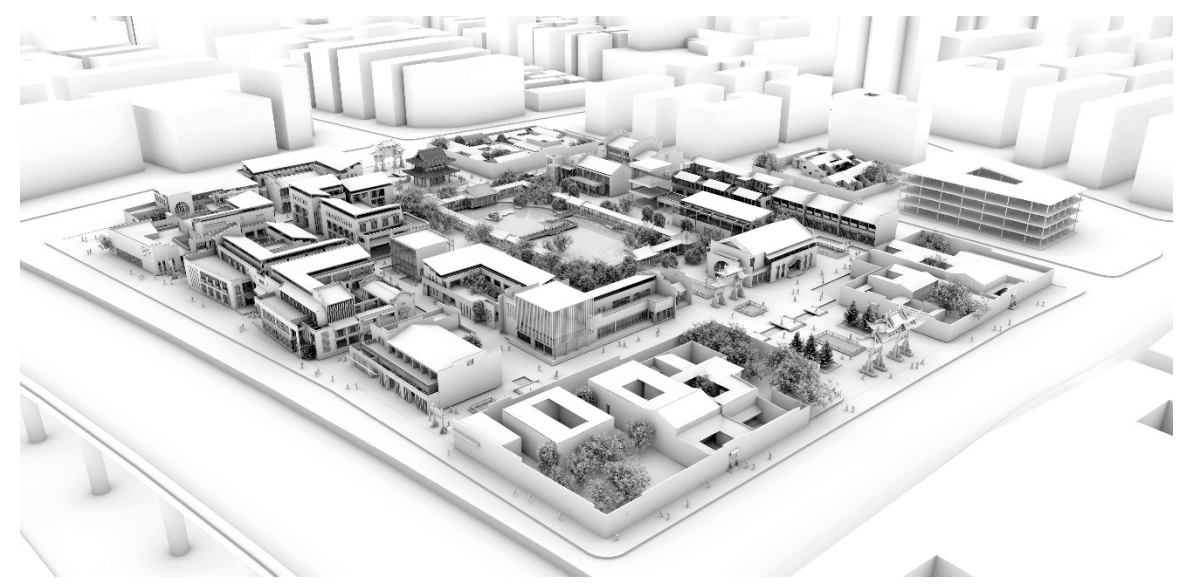

Figure 6. Perspective drawings of our disign (source: drawn by the author's design team).

conserved area while integrating the new elements to activate the plot. It adopts the multi-dimensional approach of "retention, display, reconstruction and activation" (Paxton \& Shipway, 2013). 1) Retention: The original three buildings in the block are preserved and given new functions; 2) Reconstruction: Reconstruct the Juyuan Building and the Sifang Pavilion in Desou Palace in the same year, and take the layout of the Deshou Palace in the Song Dynasty as a reference to make new plans for the venue; 3) Display: Partition the block and set it along the axis of the north-south direction of the site.. The exhibition area of the ruins of Deshou palace focuses on the historical appearance of Deshou palace; 4) Activation: Extend the daily activity time of the venue, activate the venue, and achieve the highest commercial value (Pan, 2015), and build it into a representative urban cultural tourism complex in Hangzhou.

On the basis of retaining the original cultural conservation unit of the site and rebuilding the original pattern of DeShou Palace, a new commercial industry was introduced to add a youthful element to the area. In addition, the overall plan was divided into east and west by the main axis, and the new street area was newly built. Close to the West Commercial District of Hefang Street, it mainly serves the daytime activities of tourists. The east area of the inn and lodging area is mainly composed of bar and a tea house, which satisfies the needs of tourists' night activities and maximizes the daily active time of the site.

In our research and design, based on the conservation development and utilization of the Deshou site and the inheritance of the Southern Song culture, by retaining the display reconstruction method, the historical value of the land is maximized and explored. The southern Song culture-themed tourist area forms a block and is connected in series with Wuliuxiang, Hefang Street and $\mathrm{Hu}$ Xueyan's former residence to form a larger tourist block, which will inspire greater tourism value.

\section{Conclusion}

The issue of the conservation of architectural cultural heritage is reflected in the design of urban space, which becomes a question of how the cultural value and 
meaning of heritage can be reasonably displayed in modern cities and blended with urban life. In the context of new urbanization, the display and interpretation of heritage itself have become one of the major issues of urban renewal and sustainable development (Zhou, 2007). The protection and planning of the Deshou Palace site in Hangzhou will treat cultural heritage as a valuable resource for sustainable development, carry out multi-plan discussions, and fully exploit its potential for reuse on the basis of conservation, and make it an important cultural landmark in the city.

\section{Conflicts of Interest}

The author declares no conflicts of interest regarding the publication of this paper.

\section{References}

Dong, W. (2000). Old City Renewal and Cultural Heritage Conservation. Beijing: China Architecture \& Building Press.

Dong, W. (2014). Study of the Conservation and Reconstruction for Historic Relics. Nanjing: Dongnan University Press.

Lou, Q. X. (2016). Chinese Gardens. Beijing: China Intercontinental Press.

Ma, S. Y. (2018). Ancient Architecture in Hangzhou. Hangzhou: Hangzhou Press.

Pan, G. X. (2015). Chinese Architecture History. Beijing: China Architecture \& Building Press.

Paxton, R., \& Shipway, J. (2013). Civil Heritage. Edinburgh: The Scottish Poetry Library Press.

Yang, C. M. (2006). Protection and Utilization Are Integrated in Urban Life. Beijing: China Architecture \& Building Press.

Zhou, M. (2007). Wulin Old Things. Beijing: Zhonghua Pictorial Press. 